\title{
UM OLHAR SOBRE OS TRACOS DO DARK TRIAD E OS VALORES CULTURAIS DE ESTUDANTES DE CONTABILIDADE
}

\author{
Márcia Figueredo D'Souza' \\ Gerlando Augusto Sampaio Franco Lima²
}

Resumo: A relação entre os valores culturais dos estudantes de Ciências Contábeis e os traços de personalidade, não patológicos, que compõem o Dark Triadé analisada. Trata-se de abordagem empírica, envolvendo 1.404 estudantes de contabilidade em 21 instituições públicas e privadas brasileiras. A coleta de dados, por meio de um questionário, revelou a preponderância das características que remetem ao Maquiavelismo. Sobre os valores culturais, constatou-se maior inclinação dos estudantes para o Individualismo. Observou-se ainda que quanto mais altos os níveis dos traços de personalidade do Dark Triad, maiores os valores culturais do Individualismo, Masculinidade e menor a concordância para aceitação de desigualdades hierárquicas que remetem ao valor cultural Distância ao poder. Por fim, evidenciou-se que os três traços corroboram a probabilidade de os alunos exteriorizarem valores culturais individualistas e masculinos. Esses resultados instigam a reflexão e o debate nacional sobre políticas educacionais em contabilidade que podem ser criadas pelas Instituições de Ensino Superior, com o intuito de interferir ainda no ambiente acadêmico, atitudes desonestas motivadas pelos traços de personalidade do Dark Triad e valores culturais nem sempre positivos, que geram consequências sociais, econômicas e financeiras aos principais usuários da informação contábil.

Palavras-chave: Dark Triad, Personalidade, Valores Culturais, Educação contábil.

' marciafdsouza@yahoo.com.br - Universidade do Estado da Bahia-BA. Brasil. http://orcid.org/0000-0002-3196-5396

2 gerlandolima@gmail.com - University of Illinois at Urbana-Champaign-Illinois. Estados Unidos da América. https://orcid.org/0000-0002-2414-2543 


\title{
A LOOK AT THE TRAITS OF DARK TRIAD AND THE CULTURAL VALUES OF ACCOUNTING STUDENTS
}

\begin{abstract}
The relationship between the cultural value of students of Accounting Sciences and the non-pathological personality traits that make up the Dark Triad is analyzed. This is an empirical approach involving 1,404 Accounting students in 21 Brazilian public and private institutions. Data collection, through a questionnaire, revealed the preponderance of the characteristics which refer to Machiavellianism. In regard to cultural values, students were more inclined towards Individualism. The study also observed that the higher the levels of the personality traits of the Dark Triad, the greater the cultural values of Individualism, Masculinity, and the less the agreement to accept hierarchical inequalities that refer to the cultural value Distance to power. Finally, the study evidenced that the three traits corroborate the probability of students externalizing individualistic and masculine cultural values. These results instigate the reflection and the national debate on education policies in Accounting that can be created by Higher Education Institutions, with a view to interfering early in the academic environment, with dishonest attitudes motivated by the personality traits of the Dark Triad and with not always positive cultural values, which generate social, economic and financial consequences for the main users of accounting information.
\end{abstract}

Keywords: Dark Triad; Personality; Cultural Value; Accounting Education. 


\section{INTRODUÇÃO}

A s International Education Standards (IES) são objeto de estudo da área da pesquisa científica em contabilidade. Essas normas recomendam competências técnicas, visão holística dos conhecimentos e aptidões necessárias ao profissional contábil (IES 2, 2015), bem como habilidades intelectuais, interpessoais, pessoais e organizacionais (IES 3, 2015), além de ceticismo, julgamento profissional, valores, ética e atitudes profissionais (IES 4, 2015).

Investigações na área da educação contábil que se debruçaram a estudar as normas da educação contábil destacam a importância de se considerar a personalidade (Wheeler, 2001; Mohamed \& Lashine, 2003), autoestima e autoconfiança, como elementos integradores à formação profissional em contabilidade (Mohamed \& Lashine, 2003). Nesta concepção, este estudo analisa os três traços de personalidade que compõem o Dark Triad e os valores culturais de estudantes de Ciências Contábeis, pela suposição de que essas variáveis juntas integram a formação desses estudantes e refletem-se nas atitudes e comportamentos dos futuros profissionais.

O Dark Triad é considerado uma "constelação" ou cluster que reúne conceitualmente os traços de personalidade, não patológicos, de Maquiavelismo, Narcisismo e Psicopatia (Paulhus \& Williams, 2002), mensurados pelo instrumento Short Dark Triad (SD3), elaborado por Jones e Paulhus (2014) para pesquisas de cunho social, sem o propósito de diagnóstico clínico. Conceitualmente, o traço de Narcisismo é caracterizado por grandiosidade, exibicionismo, autoadmiração, vaidade e busca de atenção. $O$ Maquiavelismo, por sua vez, é dotado de características que remetem à manipulação, cinismo, tática e estratégia. Já a Psicopatia é caracterizada pelo charme e encanto superficial, impulsividade e ausência de culpa ou remorso. Os três traços de personalidade têm em comum a insensibilidade, a desonestidade, a ausência de afabilidade e a manipulação (D'Souza, 2016).

A temática Dark Triad e cada um dos seus três traços de personalidade, individualmente, têm sido objeto de diversos estudos na área gerencial e contábil relacionados com variados assuntos, destacando-se: estilo de liderança (Nair \& Kamalanabhan, 2010), mensuração de incertezas com o uso da informação contábil (Majors, 2015), tomada de decisões oportunistas (D'Souza \& Lima, 2015), comportamento contraproducente em ambientes de trabalho (O'Boyle, Forsyth, Banks, \& McDaniel, 2012).

$\mathrm{Na}$ área educacional, os traços que compõem o Dark Triad têm sido relacionados com desonestidade acadêmica (Baughman, Jonason, Lyons, \& Vernon, 2014; Avelino \& Lima, 2014; Brunell, Staats, Barden, \& Hupp 2011), escolha de carreira na área contábil (D'Souza e Lima, 2018), fraude acadêmica (Bailey, 2015) e sobre os efeitos disfuncionais em ambientes organizacionais (Bogdanovic \& Cingula, 2015).

No que se refere às investigações que discutem a relação desses traços com valores culturais, Jonason et al. (2017) perceberam que o Dark Triad facilita a exploração oportunista e estratégica em indivíduos, como também, em algumas situações ou ambientes geograficamente diferentes, podem resultar em atitudes desejáveis e benéficas à sociedade.

Sob esse enfoque, estudos discutem a relação desses traços com valores que remetem às dimensões culturais enunciadas por Hofstede $(2001,2003)$, tais como o individualismo (Yetiser, 2014) e a distância ao poder (Robertson, Datu, Brawley, Pury, \& Mateo, 2016). O individualismo, que contrasta com o coletivismo, representa o grau em que indivíduos são integrados em grupos sociais, e a distância ao poder apresenta o grau em que a sociedade ou grupo estão dispostos a aceitar as desigualdades sociais (Shome \& Rao, 2009). 
Nesse contexto, este estudo pretende elucidar o seguinte problema de pesquisa: Qual a relação entre os valores culturais dos estudantes de Ciências Contábeis e os três traços de personalidade do Dark Triad? Foi aplicado um survey com 1.404 estudantes de Ciências Contábeis, no território brasileiro, por meio de um questionário autorrelato. Os resultados apontaram a preponderância das características que remetem ao Maquiavelismo e maior inclinação dos estudantes para o Individualismo. Observou-se ainda que quanto mais altos os níveis dos traços de personalidade do Dark Triad, maiores os valores culturais do Individualismo, Masculinidade e menor a concordância para aceitação de desigualdades hierárquicas que remetem ao valor cultural Distância ao poder. Por fim, evidenciou-se que os três traços corroboram a probabilidade de os alunos exteriorizarem valores culturais individualistas e masculinos.

Face ao exposto, os resultados do estudo contribuem para o contexto da pesquisa contábil, por oferecer aportes de caráter teórico e também prático. Teórico, por apresentar uma pesquisa multidisciplinar com interface entre a Contabilidade, Psicologia e Antropologia, sobretudo, porque a maioria das investigações que estudam os valores culturais se concentra na análise de percepção e de aderência das habilidades e competências das normas na educação contábil ou nos estilos de aprendizagem (Auyeung \& Sands, 1997; Hamann, 2011; Sugahara \& Boland, 2010; Teoh, Serang, \& Lim, 1999). Eàqueles que investigam a influência da personalidade (Wheeler, 2001) e a correlação desta com valores culturais (Briggs, Copeland \& Haynes, 2007; Kovar, Ott \& Fischer, 2003) relacionaram personalidades fundamentadas nos tipos psicológicos enunciados por Carl Gustav Jung, tais como extroversão, introversão, percepção e julgamento.

Esse estudo, portanto, se diferencia e amplia as pesquisas anteriores por trazer ao debate nacional a reflexão sobre as implicações teóricas e práticas de estudantes (futuros profissionais) ricos de características que remetem aos traços de personalidade do Dark Triad e valores culturais que podem ser manifestados nas atitudes e comportamentos indesejados dos aspirantes à profissão contábil. Embora o estudo não tenha sido aplicado entre países, os valores culturais podem ser verificados em uma organização, uma profissão, uma faixa etária, um gênero ou uma família, como afirma Hofstede (2003). A pesquisa de Hofstede, Hilal, Malvezzi, Tanure, \&Vinken (2010), por exemplo, evidenciou valores culturais diferentes entre as regiões do território brasileiro.

Importante ainda se faz discutir a interface entre os traços de personalidade e os valores culturais individualistas, masculinos e de distância ao poder, pois, segundo Kroeber e Kluckhohn (1952), a discussão sobre a influência e interação entre estas duas temáticas permite a compreensão do comportamento humano, sobretudo, porque a cultura é manifestada na, e através da personalidade.

Cabe aqui destacar que os resultados desse estudo não têm por objeto modificar os traços de personalidade dos estudantes, mas se apoia na concepção de que o ambiente acadêmico pode influenciar, ampliar ou limitar a personalidade dos indivíduos. A American Psychological Association (APA), afirma que os traços de personalidade são relativamente estáveis, consistentes, permanentes (Vandenbos, 2010), mas estão sujeitos a influências do ambiente no qual o indivíduo está inserido, como fatores sociais e culturais (Allport, 1937; 1961).

Assim, os achados permitem a reflexão sobre políticas educacionais em contabilidade que podem ser criadas pelas Instituições de Ensino Superior, com o intuito de interferir ainda no ambiente acadêmico, atitudes desonestas motivadas pelos traços de personalidade do Dark Triad e valores culturais nem sempre positivos, que geram consequências sociais, econômicas e financeiras aos principais usuários da informação contábil.

E, por fim, aponta a necessidade de as instituições de ensino e do educador enfatizarem e promoverem debates no meio acadêmico sobre as consequências de comportamentos antiéticos para o 
indivíduo, a profissão e para o público, oriundos de valores e atitudes profissionais antiéticos. Embora se observe uma preocupação da pesquisa em contabilidade sobre os dilemas éticos que os estudantes e futuros profissionais da contabilidade enfrentarão, ao longo de sua carreira, merece destaque estudos sobre fatores subjetivos, tais como a personalidade e os valores culturais, que se exteriorizam no comportamento discente e, portanto, se integra à formação dos futuros profissionais em contabilidade.

\section{REFERENCIAL TEÓRICO E HIPÓTESES DA PESQUISA}

Essa seção aborda os aspectos conceituais dos traços de personalidade do Dark Triad, os aspectos conceituais e dimensões culturais, bem como a teorização entre as variáveis, por meio da revisão de literatura de estudos anteriores sobre o Dark Triad e valores culturais.

\section{2 .1 Traços de Personalidade do Dark Triad}

Os traços de personalidade do Dark Triad (Narcisismo, Maquiavelismo e Psicopatia) apresentaram características sobrepostas em par e características comuns evidenciadas pela correlação moderada entre si, que foram corroboradas por estudos posteriores (Paulhus \& Williams, 2002; Jones \& Paulhus, 2014). Os estudos mencionados evidenciaram maiores scores para o traço Maquiavélico, seguido do Narcisismo e por último a Psicopatia.

Quando se recorre aos estudos das características dos três traços individualmente, nota-se que o Narcisismo foi um traço inicialmente considerado como um atributo relacionado ao prazer sexual pela autoadmiração exagerada e o egoísmo libidinal instintivo do indivíduo (Freud, 1914). Estudos posteriores reforçam que indivíduos narcisistas subclínicos manifestam autoridade, autossuficiência, superioridade, exibicionismo, exploração, vaidade, senso de direito (Raskin \& Terry, 1988), egocentrismo, reforço à autoimagem, desejam a exaltação, louvor, admiração, aplausos e veem os outros como inferiores, pela crença de que são diferentes e especiais (Judge, Piccolo, \& Kosalka, 2009).

Os estudos sobre o traço do Maquiavelismo consideram as concepções filosóficas de Niccolò Machiavelli, um conselheiro político italiano que publicou O Príncipe, livro de notória popularidade que pregava que a astúcia do político está baseada na mentira, cinismo, egocentrismo, manipulação interpessoal e poder de persuasão (Christie \& Geis, 1970). Uma frase que marcou as concepções de Maquiavel foi: "Os fins justificam os meios". Para ele, meios astuciosos que pudessem levar à consecução dos objetivos políticos, justificavam as atitudes dos gestores. Para tanto, usavam a estratégia, o cálculo e a racionalidade para tomar decisões (Jones \& Paulhus, 2009; Judge, Piccolo, \& Kosalka, 2009). Indivíduos ricos em maquiavelismo exteriorizam comportamentos de engano para benefício próprio (Jakobwitz \& Egan, 2006), são cínicos, frios, pragmáticos, mostram crenças imorais e insensibilidade (Rauthmann \& Will, 2011).

No tocante à Psicopatia subclínica, esse traço evidencia alta impulsividade, busca de emoções, baixa empatia, desapego emocional e ansiedade (Paulhus \& Williams, 2002). O charme superficial e enganador, egocentrismo, ausência de culpa ou remorso, engano, espírito de manipulação, comportamento irresponsável, desonestidade, ausência de princípios e uma tendência para violar as normas sociais explícitas são atributos marcantes dos psicopatas do cotidiano (Garcia, Adrianson, Archer, \& Rosenberg, 2015; Vandenbos, 2010).

A temática do Dark Triad inspira pesquisas na área de negócios e educacional. Na área de negócios, D'Souza (2016) desenvolveu um estudo com gestores brasileiros e observou a tendência à manipulação de resultados, quando motivados por uma premiação. Em sequência, D'Souza, Lima, Jones e Carré (2019) 
discutiram o comportamento menos sombrio ou brilhante quando analisados os traços moderados do Dark Triad, mesmo quando os gestores são motivados a manipular resultados para maximização de ganhos pessoais e empresariais. A discussão defende que a visão e o carisma do indivíduo narcisista, a estratégia e tática do indivíduo maquiavelista e a criatividade e o bom pensamento estratégico do indivíduo psicopata são características diferenciadoras que potencializam uma liderança bem-sucedida e integradora.

$\mathrm{Na}$ área educacional, os achados de Avelino e Lima (2014) contrapõem-se à natureza sombria dos traços narcisistas, pela verificação de que alunos do curso de Ciências Contábeis, com evidências desses traços, exteriorizaram baixa propensão à desonestidade acadêmica. Brunell et al. (2011) verificaram que os estudantes que manifestaram o exibicionismo narcisista apresentaram-se mais propensos ao cometimento de fraudes para impressionar os demais colegas e obter sucesso acadêmico.

Lima, Souza e D'Souza (2016) investigaram o narcisismo e o perfil de participantes de um congresso estudantil de contabilidade brasileiro e perceberam que aqueles ricos deste traço, apresentaram características marcantes de autoridade e exibicionismo. O sexo masculino e os estudantes de instituições privadas se revelaram mais narcisistas. Bailey (2015) também observou, entre estudantes juniores, seniores e pós-graduandos, de diversas universidades, que aqueles ricos em Psicopatia manifestam disposição para aceitar uma variedade de práticas antiéticas ou fraudulentas.

D'Souza e Lima (2015) evidenciaram com estudantes brasileiros de pós-graduação na área de negócios, a disposição para tomada de decisão oportunista, quando estudou a influência dos três traços que compõe o Dark Triad. Bogdanovic e Cingula (2015) estudaram os traços com estudantes da área de negócios croatas e canadenses e perceberam que os croatas apresentaram maiores características que remetem aos traços, justificado pelos autores pelos determinantes sociais da população croata examinada.

Os três traços do Dark triad também foram objeto de estudo de D'Souza e Lima (2018) que investigaram com estudantes brasileiros os motivos de escolha de carreira e evidenciaram que as carreiras de Auditoria e Contabilidade em organizações privadas são as mais desejadas, motivadas pela satisfação profissional e boa remuneração. Os traços impulsionaram interesses associados a Manipulação, Superioridade, Exibicionismo e Poder.

Aqui cabe ressaltar a diferença de atitudes e comportamentos quando se discute traços de personalidade. Embora as atitudes possam levar à intenção de se comportar de certa maneira, esta pode não se consumar, em função da situação ou das circunstâncias (Bowditch \& Buono, 1992). Já o comportamento "[...] são ações específicas dirigidas a um objeto-alvo, sempre ocorrendo em um contexto ou ambiente situacional e em um momento particular" (Peter \& Olson, 2009, p. 149). O presente estudo pretende então evidenciar as atitudes de estudantes, utilizando-se como instrumento de coleta de dados um questionário que utiliza a escala de concordância Likert.

Como os valores culturais podem influenciar a personalidade, conforme os estudos de Allport (1937; 1961) que consideram que os traços são características diferenciadoras que regem o comportamento e estão sujeitos a influências sociais, ambientais e culturais; variam de acordo com a situação, além de apresentarem inter-relação e sobreposição (Allport, 1937, 1961), importante se faz neste estudo discutir os aspetos conceituais e investigações que se debruçaram na abordagem cultural.

\subsection{Cultura: aspectos conceituais e dimensões}

Hofstede e Mccrae (2004) definem cultura como “A programação coletiva da mente que distingue os membros de um grupo ou sociedade, de outros" (p. 58). Assim, a mente está para o pensamento, 
sentimento e ação e, como consequência, para as crenças, atitudes e habilidades. Portanto, a cultura é: (a) coletiva, e não um atributo individual; (b) não diretamente visível, mas manifestada em comportamentos; e (c) comum para alguns, mas não para todas as pessoas.

Nessa perspectiva, Hofstede (1984) desenvolveu um estudo com 71 países, dos quais 40 países da amostra apresentaram resultados confiáveis, no período compreendido entre 1967 e 1973. O questionário foi traduzido em 20 línguas e aplicado, com empregados da empresa IBM e subsidiárias. Os achados permitiram aos autores categorizar a cultura em cinco dimensões: Distância ao Poder, Individualismo vs. Coletivismo, Masculinidade vs. Feminilidade, Aversão à incerteza e Orientação de curto prazo vs. Longo prazo, conforme tabela 1:

Tabela 1: Características das dimensões culturais propostas por Hofstede (2003)

\begin{tabular}{|c|c|}
\hline Dimensões & Características \\
\hline Distância ao poder ou Distância Hierárquica & $\begin{array}{l}\text { Hofstede (2003) observou como os membros menos influentes de organizações e instituiçōes aceitam } \\
\text { e esperam que o poder seja distribuído. Países em que o poder é detido por poucas pessoas, tal como } \\
\text { o Japão, apresentaram alto índice de distância ao poder, pois os indivíduos aceitam e esperam a } \\
\text { desigualdade hierárquica. Já em países em que o poder é distribuído largamente, como os EUA, onde } \\
\text { diversas pessoas têm influência em diversas esferas, especialmente por terem maiores oportunidades de } \\
\text { educação, emprego e renda e terem a possibilidade de alcançar o status de líderes, o índice de distância } \\
\text { ao poder apresentou-se baixo (Brislin \& Lo, 2006; Hofstede \&McCrae, 2004). }\end{array}$ \\
\hline Individualismo vs. Coletivismo & $\begin{array}{l}\text { Nessa dimensão foi observado o nível de integração de indivíduos dentro dos grupos. Nas sociedades } \\
\text { com alto índice individualista, tais como os EUA e Leste Europeu, os laços entre os indivíduos estão } \\
\text { soltos. As pessoas cuidam de si mesmas e de sua família imediata. O autointeresse, a autorrealização e } \\
\text { autoestima prevalecem nas sociedades individualistas. A relaçãa entre o empregado e o empregador é } \\
\text { uma relação calculista, de negócios, com base na suposição de vantagem mútua. Já nas sociedades com } \\
\text { baixo índice de individualismo, consideradas pelos autores como coletivistas, tais como Ásia, América do } \\
\text { Sul e África, as pessoas estão fortemente integradas, desde o nascimento e coesas em grupos (Hofstede, } \\
2003 \text {; Hofstede \& Mccrae, 2004). }\end{array}$ \\
\hline Masculinidade vs. Feminilidade & $\begin{array}{l}\text { Nessa dimensão observou-se como ocorre a divisão de papéis emocionais entre homens e mulheres. Uma } \\
\text { sociedade ou grupo foi considerado Masculino (Áustria, Itália, EUA), quando os índices de assertividade, } \\
\text { resistência, competitividade, ambição e foco no sucesso material foram altos. No que tange ao Feminino } \\
\text { observou-se os índices preponderantes de delicadeza, generosidade, modéstia e foco na qualidade de } \\
\text { vida. (Hofsted, 2001, 2003). Nesse aspecto, é importante considerar que Hofstede (2001) emprega os } \\
\text { adjetivos masculino(a) e feminino(a), de forma relativa, por entender que um homem pode se comportar } \\
\text { de forma feminina e uma mulher pode se comportar de forma masculina. }\end{array}$ \\
\hline Aversão à incerteza (medo à mudança) & $\begin{array}{l}\text { Hofstede (2003) observou o nível de stress na sociedade, face ao desconhecimento do futuro - o grau de } \\
\text { desconforto associado com situações novas, ambíguas e não estruturadas. Já na dimensão Orientação } \\
\text { de curto vs. longo prazo foi avaliada a escolha de foco para os esforços e perspectiva das pessoas com } \\
\text { orientação para o futuro ou o presente (Hofstede, 2001, 2003). }\end{array}$ \\
\hline Orientação de curto versus longo prazo & $\begin{array}{l}\text { Refere-se à escolha de foco para os esforços das pessoas: o futuro ou o presente (Hofstede, 2001; 2003). Essa } \\
\text { dimensão foi adicionada em } 1980 \text {, com base em estudos com estudantes de } 23 \text { países ao redor do mundo, } \\
\text { por meio de um questionário elaborado por pesquisadores chineses. Valores associados à orientação } \\
\text { em longo prazo são a poupança e perseverança; enquanto que os valores associados à orientação de } \\
\text { curto prazo são respeito pela tradição e cumprimento de obrigações sociais (Hofstede \& Mccrae, 2004). }\end{array}$ \\
\hline
\end{tabular}

Fonte: Elaborado pelos autores

No tocante a pesquisas no Brasil, sobre o perfil cultural brasileiro, os estudos de Hofstede, revelaram que os brasileiros se comportam de forma coletivista, masculinizada, com aceitação às desigualdades sociais, com aversão à incerteza e indulgência. Essas dimensões de cultura postuladas por Hofstede (2001; 2003) contribuíram para a pesquisa na área de negócios e contábil. O autor entende a contabilidade e seus sistemas de controle como manifestações de cultura, que se diferenciam de país para país. Ele afirma que, por trás dos rituais técnicos da contabilidade, existem valores que se originam da variação cultural entre os povos.

Na mesma linha, pesquisadores estrangeiros e nacionais se propuseram a discutir a influência cultural nos sistemas de contabilidade (Harrison \& Mckinnon, 1999; Gray, 1988), a influência da cultura no processo de harmonização das normas internacionais no Brasil (Weffort, 2005) e a cultura organizacional (Alves Filho, 2016; Casagrande, 2009).

Ademais, motivou uma pesquisa (Hofstede et al., 2010) comparativa entre as regiões brasileiras, usando o instrumento Hofstede's Values Survey Module (VSM). A pesquisa, nas cinco regiões brasileiras, aplicada com gestores, altos executivos e empregados de empresas industriais, comerciais e bancos, embora não ter tido resultados significativos para todas as dimensões, sobressaiu claramente o fator 
Individualismo versus Coletivismo. Os principais achados culturais do estudo de Hofstede et al. (2010) podem ser elencados na tabela 2:

Tabela 2: Valores culturais nas regiões brasileiras

\begin{tabular}{|l|l|}
\hline \multicolumn{1}{|c|}{ Regiões brasileiras } & \multicolumn{1}{c|}{ Características } \\
\hline Região Sul & $\begin{array}{l}\text { Região mais hierárquica, menos formal, mais individualista, e mais masculino } \\
\text { (orientada para a realização). }\end{array}$ \\
\hline Região Sudeste incluindo Brasília & Região menos masculino e mais orientada para o curto prazo. \\
\hline Região Centro-Oeste & Área menos formal. \\
\hline Região Nordeste & Área menos hierárquica, mais formal e menos masculino. \\
\hline Região Norte & $\begin{array}{l}\text { Área marcadamente informal, coletivista e muito masculino (alto nível de } \\
\text { assertividade). }\end{array}$ \\
\hline
\end{tabular}

Fonte: Adaptado de Hofstede et al. (2010)

Merece destaque ainda estudos que discutem as dimensões culturais na área da educação contábil. Auyeung e Sands (1997) perceberam que os estudantes da sociedade chinesa têm uma predisposição para atividades coletivistas. Já os estudantes australianos valorizam altamente a autossuficiência e realização individual. Nessa mesma linha de estudo, os achados de Sugahara e Baland (2010) sugeriram que os japoneses gostam de aprender observando, devido à natureza relativamente coletiva direcionada à aprendizagem. Em contraste, os estudantes australianos, que tendiam mais ao individualismo na sua aprendizagem, estavam mais dispostos a aprender com a prática.

Teoh et al. (1999) observaram que há diferenças de percepção cultural, revelando os indonésios como coletivistas e os australianos como individualistas. Hamann (2011) investigou a relação entre as dimensões culturais e o estilo de aprendizagem de 311 estudantes de Ciências Contábeis do Distrito Federal. Os resultados sugeriram uma predominância para valores culturais de masculinidade, pela maior evidência de afirmação, competitividade e maiores ambições, associada a um estilo de aprendizagem que privilegia a teoria à prática.

A próxima seção traz a revisão de literatura sobre a teorização das variáveis: traços de personalidade do Dark Triad e os valores culturais.

\subsection{Dark Triade valores culturais: estudos anteriores}

Robertson et al. (2016) analisaram estudantes dos EUA e das Filipinas para perceberem a influência dos traços do Dark Triad com o comportamento contraproducente no ambiente laboral, utilizando a dimensão cultural distância ao poder como uma das variáveis de controle. O traço narcisista se relacionou positivamente à dimensão distância ao poder na amostra de estudantes filipinos, enquanto que os estudantes dos EUA, que demonstraram traços de psicopatia, também se relacionaram positivamente à distância ao poder.

Yetiser (2014) observou que indivíduos de países de culturas individualistas apresentaram maior disposição para traços maquiavélicos, quando comparados com países de cultura coletivista. Como o maquiavélico projeta ganhos individuais em detrimento de ganhos coletivos, os indivíduos em sociedades individualistas tendem a manipular outros para alcançar seu próprio objetivo. Por outro lado, indivíduos de sociedades com culturas coletivistas projetam o ganho da comunidade mais do que os seus próprios; portanto, demonstram menos maquiavelismo.

Jonason et al. (2017) verificaram, em seis países, as relações entre as diferenças individuais de autoconstruções independentes (ambição, competição, características masculinas) e interdependentes 
(comunhão, generosidade, características femininas) e os traços do Dark Triad. O maquiavelismo e o narcisismo apresentaram associação mais forte com a independência. Os homens apresentaram maiores pontuações que as mulheres nos traços do Dark Triad, em todos os países pesquisados.

Os estudos apresentados motivam a continuidade de investigações que explorem o efeito dos traços de personalidade do Dark Triade dos valores culturais, em particular os valores relacionados aos valores culturais que remetem às dimensões Masculinidade versus Feminilidade, Individualismo versus Coletivismo e Distancia ao poder, sobretudo porque as características desses valores guardam maior relação com as características dos traços de personalidade em estudo, tais como, ambição, competitividade, autoestima, autointeresse e não aceitação hierárquica.

Isso posto, elencam-se as seguintes hipóteses de pesquisa:

- H1: Existe uma correlação significativa entre os traços que compõe o Dark Triade os valores culturais de Masculinidade, Individualismo e Distância ao poder.

- H2: Os estudantes de Ciências Contábeis com altos traços de personalidade que compõe o Dark Triad são mais propensos a valores masculinos.

- H3: Os estudantes de Ciências Contábeis com altos traços de personalidade que compõe o Dark Triad são mais propensos a valores individualistas.

- H4: Os estudantes de Ciências Contábeis com altos traços de personalidade que compõe o Dark Triad são menos propensos à aceitação de valores culturais da Distância ao poder.

Sobre os níveis dos traços, propõe-se observar o comportamento de indivíduos em grau baixo, moderado e alto. Conforme D'Souza, Lima, Jones, \& Carré (2018) o nível moderado pode revelar atitudes desejáveis daqueles que exibem os traços do Dark Triad.

\section{METODOLOGIA}

\subsection{Abordagem, estratégia e amostra da pesquisa}

O survey foi eleito como estratégia de coleta de dados, com base na aplicação de questionário autorrelato, respondido de forma presencial e na modalidade on-line, no período de novembro a dezembro de 2016, compreendendo o Termo de Consentimento Livre e Esclarecido (TCLE) e o levantamento do perfil demográfico, social, cultural e de personalidade de estudantes de Ciências Contábeis. O SD3 (Jones \& Paulhus, 2014) foi aplicado para mensuração dos traços de personalidade do Dark Triad. Os perfis culturais Individualismo vs. Coletivismo, Masculinidade vs. Feminilidade e Distância ao poder foram verificados por meio de assertivas que contêm componentes dos elementos conceituais dessas dimensões culturais (Hofstede, 2001).

A amostra foi selecionada de forma não probabilística e engloba estudantes matriculados em cursos de graduação em Ciências Contábeis de 21 Instituições de Ensino Superior (IES) brasileiras, sendo 12 públicas e 9 privadas. Embora se conheça os resultados do estudo de Hofstede (2001) e Hofstede at al (2010) no território brasileiro, com profissionais de mercado e pós-graduandos, a presente pesquisa foi aplicada com estudantes de graduação (futuros profissionais) e traz a discussão e interface com a temática do Dark Triad, conteúdo ainda pouco exploradas na área da educação contábil.

\subsection{Variáveis de pesquisa}

A Figura 1 ilustra o desenho da pesquisa, detalhando as variáveis e respectivas operacionalizações da investigação. 


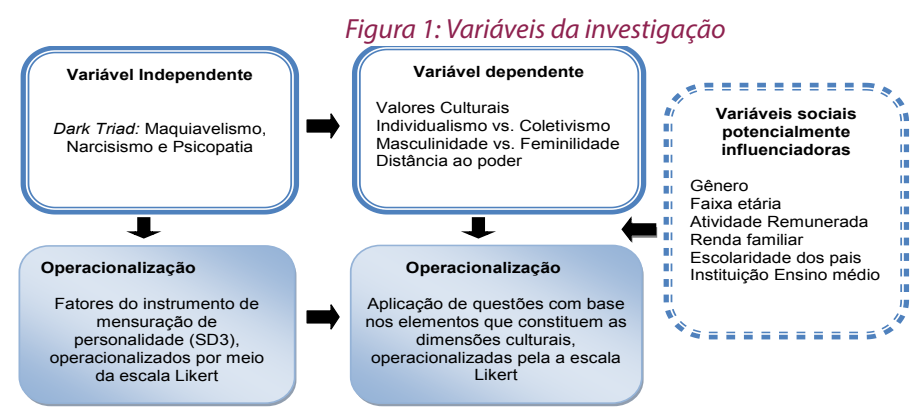

Fonte: Elaborado pelos autores

O Dark Triadé a variável independente, por explicar os valores culturais do Individualismo vs. Coletividade, Masculinidade vs. Feminilidade e Distância ao poder. Os estudos de Hofstede e McCrae (2004) aplicado em 33 países apoiam essa concepção de que traços de personalidade se correlacionam com as dimensões culturais propostas por Hofstede (2003).

Consideram-se, ainda, as variáveis demográficas (Gênero e Faixa etária) e sociais (Atividade Remunerada, Renda familiar, Escolaridade dos pais e Instituição Ensino médio) como potencialmente influenciadoras no modelo apresentado, pois segundo Hambrick (2007) características como idade, ocupação na empresa, experiência funcional, educação, raízes socioeconômicas e posição financeira, influenciam na personalidade dos indivíduos e possibilitam uma visão psicológica do comportamento humano.

\subsection{Instrumento de coleta de dados e Procedimentos estatísticos}

3.3.1 Perfil de personalidade: SD3

Para a medição dos traços de personalidade foi utilizado o SD3 (Jones \& Paulhus, 2014), composto por 27 assertivas, no formato Likert (1 a 7 pontos), traduzido para a língua portuguesa por D'Souza (2016), conforme tabela 3.

Tabela 3: Assertivas do instrumento SD3 (Jones e Paulhus, 2014)

\begin{tabular}{|l|}
\hline \multicolumn{1}{|c|}{ Maquiavelismo } \\
\hline Não é prudente contar meus segredos \\
\hline Em geral, as pessoas não trabalham com afinco, a menos que tenham que fazê-lo \\
\hline Você precisa ter pessoas importantes ao seu lado, não importa a que custo \\
\hline Evite o conflito direto com os outros, porque eles poderão ser úteis no futuro \\
\hline É prudente manter-se a par de informações que você poderá usar contra as pessoas mais tarde \\
\hline Você deve esperar pelo momento certo para dar o troco às pessoas \\
\hline Existem coisas que você deve esconder das outras pessoas porque elas não precisam saber \\
\hline Certifique-se de que seus planos beneficiam você, não os outros \\
\hline A maioria das pessoas pode ser manipulada \\
\hline \\
\hline As pessoas me veem como um líder natural \\
\hline Eu detesto ser o centro das atenções $R$ \\
\hline Muitas atividades em grupo tendem a ser entediantes sem mim \\
\hline Eu sei que sou especial, porque as pessoas vivem dizendo isso \\
\hline Eu gosto de conhecer pessoas importantes \\
\hline Sinto-me envergonhado quando recebo elogios $R$ \\
\hline
\end{tabular}




\begin{tabular}{|l|}
\hline Eu já fui comparado a pessoas famosas \\
\hline Eu sou uma pessoa comum $R$ \\
\hline Eu insisto em receber o respeito que mereço \\
\hline \\
\hline Gosto de retaliar pessoas que têm autoridade Psicopatia \\
\hline Eu evito situações perigosas $R$ \\
\hline Revide tem que ser rápido e desagradável \\
\hline As pessoas geralmente dizem que eu estou fora de controle \\
\hline É verdade que eu posso ser maldoso com os outros \\
\hline As pessoas que aprontam comigo sempre se arrependem \\
\hline Eu nunca tive problemas com a lei $R$ \\
\hline Eu gosto de implicar com pessoas malsucedidas \\
\hline Direi qualquer coisa para conseguir o que quero \\
\hline
\end{tabular}

Fonte: D'Souza (2016)

Nota1: Em consonância com o instrumento de pesquisa, as respostas às assertivas com o " $R$ " são revertidas: resposta 1 para 5; resposta 2 para 4 e a resposta 3, mantém sem reversão.

Para conhecer os níveis dos traços de personalidade, foi adotado o seguinte critério: inicialmente foi mensurada a média de cada indivíduo e do grupo (variável quantitativa), sendo, na sequência, utilizado o tercil para dividir o grupo em três faixas: baixo, moderado e alto traços (variável qualitativa). Essa metodologia de cálculo coaduna com a prática corrente de estudos na área de psicologia e da área contábil (Johnson, Kuhn, Apostolou, \& Hassel, 2012; Majors, 2015).

Importa considerar que, embora os três traços possuam características comuns e estarem moderadamente correlacionados positivamente, são constructos conceitualmente distintos (Paulhus \& Williams, 2002; Jones \& Paulhus, 2014), fato que justifica a separação teórica e empírica, para os estudos que abordam essa temática (O'Boyle et al., 2012). Nessa direção, esta pesquisa trabalha com a análise individual e o efeito combinado dos três traços.

\subsubsection{Perfil cultural}

As assertivas culturais foram elaboradas pela adaptação do instrumento de pesquisa idealizado por Hofstede (2003) e Casagrande (2009), tomando por base a teoria e elementos que caracterizam as dimensões culturais. Considerou-se para o Individualismo, assertivas que remetem à autoestima, ao autointeresse, a autorrealização, a relação de troca vantajosa e ao interesse na família imediata. Para a Masculinidade, a assertividade, a resistência, o sucesso material e a competitividade. E, para a Distância ao poder, foi estimada a desigualdade social, dependência e status da dimensão, conforme tabela 4. Mediu-se o grau de concordância atitudinal dos estudantes por meio da escala Likert (1 a 7 pontos).

Tabela 4: Assertivas do instrumento de medição dos valores culturais

\begin{tabular}{|l|l|}
\hline \multicolumn{1}{|c|}{ Masculinidade } & \\
\hline Assertivas & Características \\
\hline O sucesso material é mais importante que o pessoal & Foco no sucesso material \\
\hline Gosto de competir com meus colegas de universidade e/ou do trabalho & Competitividade \\
\hline Persistência é o melhor caminho para alcançar melhores resultados & Resistência \\
\hline Defendo minhas opiniões com segurança & Assertividade \\
\hline Assumir as melhores funções na empresa é uma meta a ser alcançada & Ambição \\
\hline \multicolumn{1}{|c|}{ Individualismo } & \\
\hline Assertivas & Características \\
\hline
\end{tabular}




\begin{tabular}{|l|l|}
\hline A obtenção de títulos e diplomas aumenta o valor econômico e o amor próprio & Autointeresse e Autoestima \\
\hline $\begin{array}{l}\text { Não gosto de formar laços com pessoas estranhas. Cada um deve ocupar de si mesmo e de sua } \\
\text { familia mais próxima }\end{array}$ & Laços soltos \\
\hline É importante maximizar meus ganhos & Autointeresse \\
\hline Em minhas decisões busco primeiro benefícios próprios, em seguida, o coletivo. & Autointeresse \\
\hline A autorrealização é base para o sucesso & Autorrealização \\
\hline A autoestima é imprescindível para minha motivação na universidade e/ou no trabalho & Autoestima \\
\hline A relação de trabalho é uma transação comercial e não familiar & Relação calculista \\
\hline \multicolumn{1}{|c|}{ Distância ao poder } & \\
\hline Assertivas & Características \\
\hline As desigualdades entre as pessoas devem existir e são desejáveis & Distância hierárquica \\
\hline Quem tem menos poder deve depender de quem tem mais & Distância hierárquica \\
\hline Os privilégios e símbolos de status devem existir e são bem vistos & Distância hierárquica \\
\hline Tenho receio de expressar desacordo de decisões dos meus superiores & Distância hierárquica \\
\hline Quem tem menos poder deve depender de quem tem mais & Distância hierárquica \\
\hline
\end{tabular}

Fonte: Adaptada de Hofstede (2003) e Casagrande (2009)

Cabe aqui mencionar o nível de confiabilidade satisfatório do questionário aplicado no estudo. Para as variáveis dos traços de personalidade, o Alfa de Cronbach indicou nível de 0,792; para as variáveis dos valores culturais, nível de 0,767 e quando se incluiu todas as variáveis da investigação o foi nível de 0,836.

\subsubsection{Procedimentos estatísticos}

Foram aplicadas as seguintes técnicas estatísticas: descritiva, correlação, testes de hipóteses e regressão logística, para validar as hipóteses. A técnica descritiva oportunizou o cálculo das médias, frequências e desvios-padrão.

O teste de hipótese de diferença entre médias Anova de um fator e os testes de Mann-Whitney e Kruskal-Wallis foram utilizados para verificar se existiam diferenças entre os níveis dos traços de personalidade do Dark Triad e os valores culturais e variáveis demográficas e sociais.

A regressão logística foi aplicada para dar robustez aos resultados e devido à natureza binária das variáveis dependentes dos valores culturais, permitindo verificar os efeitos de cada uma das variáveis inseridas no modelo. Assim, foi possível verificar a probabilidade de ocorrência de um determinado evento e a contribuição individual de cada um dos previsores e dar mais robustez aos resultados do estudo.

\section{RESULTADOS E DISCUSSÃO}

Os resultados estão apresentados conforme a seguinte divisão: Perfil dos participantes e o DarkTriad, os valores culturais e a influência das variáveis demográficas e sociais.

4.1 Perfil dos Participantes

A pesquisa foi realizada no território brasileiro e obteve 1.404 respostas de estudantes de Ciências Contábeis. No tocante ao perfil demográfico, $58,8 \%$ são do gênero feminino, com maior prevalência da faixa etária entre 17 e 25 anos (61,5\%), de solteiros (79,7\%) e ensino médio cursado em escola pública (63,5\%). A amostra revela que 57,4\% dos alunos cursam o bacharelado na rede pública, com maior incidência dos semestres letivos $2^{\circ}(12 \%), 7^{\circ}(12,2 \%)$ e $8^{\circ}(17,3 \%)$. Os pais detêm o ensino médio completo (33,5\%) - maior nível de escolaridade. Quanto à fonte de renda, a maioria já exerceu ou exerce atividade 
remunerada (85,5\%), auferindo renda familiar entre dois e quatro salários mínimos (52,6\%). No período do survey o salário mínimo mensal era de $\mathrm{R} \$ 937,00$.

\subsection{Dark Triad, os Valores Culturais e a influência das variáveis demográficas e sociais}

Dos três traços de personalidade do Dark Triad, o Maquiavelismo apresentou a maior média $(3,556)$ (Tabela 5), significando maior propensão dos estudantes ao uso de estratégias. Este resultado é corroborado pelos estudos de Jones e Paulhus (2014), Paulhus e Williams (2002), D'Souza (2016); D'Souza e Lima (2015), Bogdanovic e Cingula (2015).

Sobre as dimensões culturais, os estudantes demonstraram maior inclinação para os valores culturais individualistas, apresentando o maior escore $(\mu=4,530)$, seguido dos valores de Masculinidade $(\mu=4,471)$, sendo a dimensão Distância ao poder a menor média $(\mu=2,201)$ (nessa dimensão o baixo nível significou menor concordância para as assertivas: "as desigualdades entre as pessoas devem existir e são desejáveis", "quem tem menos poder deve depender de quem tem mais"e "os privilégios e símbolos de status devem existir e são bem vistos") (Tabela 5).

Aqui cabe a comparação com os resultados do estudo de Hofstede1 para a sociedade brasileira. Segundo o autor, o Brasil é coletivista, masculino e tem altos índices de aceitação a desigualdades sociais. Já os resultados da presente pesquisa, revelaram que os estudantes têm mais valores culturais individualistas tais como autointeresse, autoestima e autorrealização, valores que podem minimizar o bem comum e o coletivo no ambiente acadêmico e profissional.

Ademais, os estudantes evidenciam não terem receio em discordar da liderança e de não aceitarem as desigualdades sociais, resultados que divergem do estudo de Hofstede1 no Brasil, que segundo o autor a sociedade acredita que a hierarquia deve ser respeitada e as desigualdades entre as pessoas são aceitáveis. Nas empresas, há um chefe que assume total responsabilidade. Observa-se assim, uma mudança de concepção na amostra analisada, que pode ser consequência da formação na área de negócios, que impulsiona os estudantes a buscarem melhores colocações no mercado de trabalho. $\mathrm{O}$ respeito é importante, mas manter uma postura de subordinação nem sempre é o melhor caminho, pois pode impedir a luta por uma carreira de sucesso dentro das empresas.

No tocante a estudos com estudantes, os resultados do presente estudo são corroborados pelos achados de Auyeung e Sands (1997), Sugahara e Boland (2010) e Teoh, Serang e Lim (1999), com estudantes australianos, que privilegiam a autossuficiência e a realização pessoal. No tocante à amostra de estudantes de contabilidade brasileiros, Hamann (2011) verificou a predominância dos estudantes para as características masculinas.

Tabela 5: Estatística descritiva dos traços de personalidade do Dark Triade das dimensões culturais

\begin{tabular}{|l|l|l|l|l|l|}
\hline \multicolumn{1}{|c|}{ Variáveis } & No de alunos & \multicolumn{1}{c|}{ Mínimo } & \multicolumn{1}{c|}{ Máximo } & \multicolumn{1}{c|}{ Média } & \multicolumn{1}{c|}{ Desvio-padrão } \\
\hline Maquiavelismo & 1,404 & 1.0 & 7.0 & 3.556 & 1.0794 \\
\hline Narcisismo & 1,404 & 1.0 & 6.9 & 3.493 & 0.8938 \\
\hline Psicopatia & 1,404 & 1.0 & 6.7 & 2.145 & 0.8408 \\
\hline Masculinidade & 1,404 & 1.0 & 7.0 & 4.471 & 0.9552 \\
\hline Individualismo & 1,404 & 1.0 & 7.0 & 4.530 & 0.9946 \\
\hline Distância do poder & 1,404 & 1.0 & 7.0 & 2.201 & 1.3557 \\
\hline N válido (de lista) & 1,404 & \multicolumn{5}{|c|}{ Fonte: Dados da pesquisa (2017) } \\
\hline
\end{tabular}


Quando se analisa a frequência dos traços por nível, tomando por base o tercil, observa-se que, embora haja a predominância de baixa disposição dos estudantes para Maquiavelismo 35,6\%, Narcisismo $37,6 \%$ e Psicopatia 35,8\%, observa-se uma frequência significativa e equilibrada de estudantes com altos níveis de Maquiavelismo (31,6\%), Narcisismo (31,1\%) e Psicopatia (29,3\%). (Tabela 6)

Os resultados evidenciam ainda a preponderância do traço Maquiavelismo, corroborando a investigação de D'Souza (2016), que também encontrou percentuais significativos de Maquiavelismo (38\%) e Psicopatia $(41,1 \%)$, quando pesquisou gestores brasileiros. Esse procedimento possibilita a percepção da força dos traços para diferenciar a maior ou menor disposição do indivíduo para imprimir condutas sombrias no ambiente educacional e futuramente no profissional. Como a Psicopatia apresentou a menor média em relação aos outros dois traços, o tercil também reflete menor valor entre as faixas alta, moderada e baixa.

Tabela 6: Frequência dos traços por nível

\begin{tabular}{|c|c|c|c|c|c|c|c|c|c|c|}
\hline & & \multicolumn{2}{|c|}{ Maquiavelismo } & \multirow{2}{*}{$\begin{array}{c}\text { Faixas } \\
\text { Tercil }\end{array}$} & \multicolumn{2}{|c|}{ Narcisismo } & \multirow{2}{*}{$\begin{array}{c}\text { Faixas } \\
\text { Tercil }\end{array}$} & \multicolumn{2}{|c|}{ Psicopatia } & \multirow{2}{*}{$\begin{array}{c}\text { Faixas } \\
\text { Tercil }\end{array}$} \\
\hline \multicolumn{2}{|c|}{ Níveis dos traços } & $\mathrm{N}$ & $\mathrm{P}(\%)$ & & $\mathrm{N}$ & $\mathrm{P}(\%)$ & & $\mathrm{N}$ & $\mathrm{P}(\%)$ & \\
\hline \multirow{4}{*}{ Válido } & Baixo & 500 & 35,6 & $<3,00$ & 528 & 37,6 & $<3,1$ & 503 & 35,8 & $<1,7$ \\
\hline & Moderado & 461 & 32,8 & $3 \geq 4$ & 439 & 31,3 & $3,1 \geq 3,9$ & 490 & 34,9 & $1,7 \geq 2,3$ \\
\hline & Alto & 443 & 31,6 & $>4$ & 437 & 31,1 & $>3,9$ & 411 & 29,3 & $>2,3$ \\
\hline & Total & 1.404 & 100,0 & & 1404 & 100,0 & & 1.404 & 100,0 & \\
\hline
\end{tabular}

Fonte: Dados da pesquisa (2017)

Quando se analisa a correlação entre os traços de personalidade e as dimensões culturais, os resultados permitem verificar (Tabela 7), uma correlação positiva e significativa entre os traços de personalidade do Dark Triad e as dimensões de cultura. Hofstede e McCrae (2004) já apontavam essa correlação positiva entre traços de personalidade e as dimensões culturais. Nessa mesma linha, Robertson et al. (2016) perceberam em estudantes dos EUA, que exibiram traços de psicopatia, a relação positiva aos valores culturais sobre distância ao poder, e em estudantes filipinos a relação positiva entre o traço narcisista e a dimensão distância ao poder. Jonason et al. (2017) perceberam que os maquiavélicos e narcisistas apresentaram associação mais forte com os valores de ambição, competição que remetem à características masculinas.

Os dados sugerem que a característica calculista e estratégica do indivíduo maquiavélico impulsiona a busca do sucesso material, por meio de trocas vantajosas, com fins de autorrealização e da autoestima. A diferença social não é aceitável, dado que os indivíduos maquiavélicos buscam reputação e status. Nesse aspecto, o traço maquiavélico promove a luta por melhores oportunidades de trabalho, poder e renda.

Para o traço narcisista, esse resultado coaduna as características de autoestima, autointeresse e autorrealização exteriorizados por pessoas individualistas e a competitividade exibida por pessoas com valores masculinos. O narcisista busca poder, pela dificuldade de estar subordinado ou ter qualquer nível de dependência com outras pessoas, especialmente devido ao seu comportamento aflorado em vaidade, autoridade, arrogância e complexo de grandiosidade. Com relação ao traço da Psicopatia, nota-se a associação entre características como autopromoção, busca por emoções e ausência de culpa ou remorso dos psicopatas e as características que remetem às três dimensões culturais. Esses achados confirmam a hipótese $\mathrm{H} 1$. 
Tabela 7: Correlação Pearson (médias)

\begin{tabular}{|c|c|c|c|c|c|c|}
\hline Pearson & Maquiavelismo & Narcisismo & Psicopatia & Masculinidade & Individualismo & Distância ao poder \\
\hline Maquiavelismo & 1 & & & & & \\
\hline Narcisismo &, $\left.3699^{* *}\right)$ & 1 & & & & \\
\hline Psicopatia &, $460(* *)$ &, $\left.3677^{* *}\right)$ & 1 & & & \\
\hline Masculinidade &, $346(* *)$ &, $\left.3311^{* *}\right)$ &, $201(* *)$ & 1 & & \\
\hline Individualismo &, $431(* *)$ &, $\left.301{ }^{* *}\right)$ &, $242(* *)$ &, $523(* *)$ & 1 & \\
\hline $\begin{array}{l}\text { Distância ao } \\
\text { poder }\end{array}$ &, $\left.426{ }^{* * *}\right)$ &, $298^{(* *)}$ &, $\left.389^{* *}\right)$ &, $280(* *)$ &, $297 * * *$ & 1 \\
\hline
\end{tabular}

$(* *) p<, 01$, bi-caudal.

Fonte: Dados da pesquisa (2017)

Com o intuito de evidenciar diferença significativa entre os traços de personalidade do Dark Triade as dimensões culturais, aplicou-se o teste Anova. Na análise da dimensão Masculinidade, por meio do teste $F$, encontrou-se $(F(2,1401)=77,957, p=0,000)$ para o Maquiavelismo, $(F(2,1401)=73,286 p=0,000)$ para o Narcisismo e $(F(2,1401)=21,628, p=0,000)$ para a Psicopatia. Esses resultados indicam que há diferença na dimensão cultural Masculinidade entre os indivíduos, para os níveis baixo, moderado e alto de Maquiavelismo, Narcisismo e Psicopatia, o que confirma a hipótese H2: Quanto mais fortes os traços do Dark Triad, maiores os valores de Masculinidade dos estudantes de contabilidade.

Este resultado permite inferir que o senso de grandiosidade do indivíduo narcisista, a estratégia do maquiavelista e impulsividade do psicopata, influenciam valores que remetem à busca de sucesso material e competitividade nesta amostra.

Tabela 8: Anova - Níveis dos traços de personalidade do Dark Triade Masculinidade (média)

\begin{tabular}{|c|c|c|c|c|c|c|c|c|c|}
\hline & \multicolumn{3}{|c|}{ Maquiavelismo } & \multicolumn{3}{|c|}{ Narcisismo } & \multicolumn{3}{|c|}{ Psicopatia } \\
\hline & DF & $\mathrm{F}$ & Sig. & DF & $\mathrm{F}$ & Sig. & DF & $\mathrm{F}$ & Sig. \\
\hline $\begin{array}{l}\text { Entre grupos } \\
\text { Nos grupos }\end{array}$ & $\begin{array}{l}2 \\
1.401\end{array}$ & 77,957 &, $000\left(^{*}\right)$ & $\begin{array}{l}2 \\
1.401\end{array}$ & 73,286 & , $\left.000{ }^{* *}\right)$ & $\begin{array}{l}2 \\
1.401\end{array}$ & 21,628 &, $\left.000^{*}\right)$ \\
\hline Total & 1.403 & & & 1.403 & & & 1.403 & & \\
\hline
\end{tabular}

Fonte: Dados da pesquisa (2017)

De forma similar, o teste $\mathrm{F}$ foi aplicado para se verificar a diferença entre os três traços de personalidade do Dark Triad e o Individualismo. Os resultados evidenciaram $(F(2,1401)=115,001, p=0,000)$ para o Maquiavelismo, $(F(2,1401)=64,192, p=0,000)$ para o Narcisismo e $(F(2,1401)=34,466, p=0,000)$ para a Psicopatia e confirmam a hipótese H3 - quanto mais altos os traços do Dark Triad, maiores os valores culturais de Individualismo dos estudantes.

Este resultado sugere que o egoísmo, a autopromoção e a autoestima, características comuns aos indivíduos narcisistas e psicopatas, e o cálculo estratégico de indivíduos maquiavelistas influenciam valores que remetem ao autointeresse, autorrealização e à relação de troca vantajosa dos estudantes de contabilidade da amostra em análise.

Tabela 9: Anova - Níveis dos traços do Dark Triade Individualismo (média)

\begin{tabular}{|c|c|c|c|c|c|c|c|c|c|}
\hline & \multicolumn{3}{|c|}{ Maquiavelismo } & \multicolumn{3}{|c|}{ Narcisismo } & \multicolumn{3}{|c|}{ Psicopatia } \\
\hline & DF & $\mathrm{F}$ & Sig. & DF & $\mathrm{F}$ & Sig. & DF & $\mathrm{F}$ & Sig. \\
\hline $\begin{array}{l}\text { Entre grupos } \\
\text { Nos grupos }\end{array}$ & $\begin{array}{l}2 \\
1.401\end{array}$ & 115,001 & ,000 & $\begin{array}{l}2 \\
1.401\end{array}$ & 64,192 & ,000 & $\begin{array}{l}2 \\
1.401\end{array}$ & 34,466 & ,000 \\
\hline Total & 1.403 & & & 1.403 & & & 1.403 & & \\
\hline
\end{tabular}

Fonte: Dados da pesquisa (2017) 
O teste F também apresentou diferenças significativas entre os três traços de personalidade do Dark Triad e a dimensão Distância do poder, ao se analisar os valores $(F(2,1401)=127,166, p=0,000)$ para o Maquiavelismo, $(F(2,1401)=67,126, p=0,000)$ para o Narcisismo e $(F(2,1401)=77,161, p=0,000)$ para a Psicopatia. Os achados confirmam a hipótese $\mathrm{H} 4$ e permitem inferir que quanto mais altos os traços do Dark Triadmenor a propensão para a aceitação cultural sobre a Distância ao poder entre os estudantes de contabilidade. Estes demonstraram uma não aceitação pela desigualdade hierárquica na sociedade, não coadunando os achados do estudo de Hofstede et al. (2010). Isso demonstra que os estudantes esperam maior igualdade e oportunidades de educação, emprego e renda.

Tabela 10: Anova - Níveis dos traços do Dark Triade Distância ao poder (média)

\begin{tabular}{|c|c|c|c|c|c|c|c|c|c|}
\hline & \multicolumn{3}{|c|}{ Maquiavelismo } & \multicolumn{3}{|c|}{ Narcisismo } & \multicolumn{3}{|c|}{ Psicopatia } \\
\hline & DF & $\mathrm{F}$ & Sig. & DF & $\mathrm{F}$ & Sig. & DF & $\mathrm{F}$ & Sig. \\
\hline $\begin{array}{l}\text { Entre grupos } \\
\text { Nos grupos }\end{array}$ & $\begin{array}{l}2 \\
1.401\end{array}$ & 127,166 & , 000 & $\begin{array}{l}2 \\
1.401\end{array}$ & 67,126 &, 000 & $\begin{array}{l}2 \\
1.401\end{array}$ & 77,161 & ,000 \\
\hline Total & 1.403 & & & 1.403 & & & 1.403 & & \\
\hline
\end{tabular}

Fonte: Dados da pesquisa (2017)

Os testes de Bonferroni também confirmam que os estudantes com baixos e moderados níveis dos traços de personalidade do Dark Triad exibem diferença significativa quanto à concordância sobre os valores culturais de Masculinidade, Individualismo e Distância do poder, quando comparados com estudantes com altos níveis. O teste de Tukey corrobora esses resultados, ao exibir a formação de três subconjuntos diferentes para cada nível dos traços de personalidade do Dark Triad.

Este resultado permite inferir que os estudantes com traços moderados do Dark Triadse comportam de forma diferente daqueles que exibem baixos e altos traços, denotando que possuem características mais peculiares que podem resultar em atitudes desejáveis e salutares dos indivíduos que exteriorizam esses traços, conforme discussão de D’Souza et al. (2019), Jonason, Webster, Schmitt, Li e Crysel (2012) e Jones e Paulhus (2014). Por exemplo, na amostra em estudo, os estudantes com níveis moderados de Maquiavelismo apresentaram maior inclinação para valores masculinos (50,1\%) e aceitação à desigualdade hierárquica (54,2\%). Os narcisistas moderados também manifestaram maior aceitação à hierarquia (51\%), enquanto que os estudantes com níveis moderados de Psicopatia apresentaram baixas inclinações para os valores das três dimensões culturais.

Com o desígnio de evidenciar a influência das variáveis demográficas e sociais sobre os traços de personalidade, aplicou-se o teste de diferença entre médias. É possível perceber que o gênero, a atividade remunerada, a renda, a escolaridade dos pais, o tipo de instituição em que foi cursado o ensino médio, diferenciam-se quando são analisados os traços maquiavélicos.

O traço narcisista demonstrou diferença na presença de gênero, faixa etária, renda, escolaridade dos pais e tipo de instituição em que foi cursado o ensino médio. Os níveis de Psicopatia evidenciaram ainda uma diferença na presença de gênero, faixa etária, renda, escolaridade dos pais e tipo de instituição em que foi cursado o ensino médio. Esse resultado possibilita a inferência de que os fatores sociais são potencialmente influenciadores dos traços de personalidade do Dark Triad, como asseguram Hambrick (2007), Allport (1937; 1961).

Os três traços do Dark Triadapresentaram diferenças na presença de gênero, escolaridade dos pais e tipo de instituição em que foi cursado o ensino médio. Isso denota que os estudantes de Ciências Contábeis do gênero masculino têm maior inclinação do que o gênero feminino para manifestar os traços 
do Dark Triad, possivelmente por exibirem maiores características de insensibilidade, impulsividade, autossuficiência, egocentrismo, frieza emocional e cálculos estratégicos.

Nesse aspecto, estes achados são corroborados pela investigação de Jones e Paulhus (2014) ao evidenciarem que os homens manifestaram escores mais elevados para os três traços do Dark Triad. Bogdanovic e Cingula (2015) constataram maiores escores de Maquiavelismo e Psicopatia para o gênero masculino. Lima, Souza e D'Souza (2016) também comprovaram que estudantes do gênero masculino são mais narcisistas. Jonason et al. (2017) perceberam que os homens obtiverem maiores pontuações dos três traços que compõem o Dark Triad em seis países com culturas diferentes.

No que se refere à escolaridade dos pais, observou-se que os estudantes em que os pais possuem Especialização, Mestrado ou Doutorado apresentaram maior frequência para os altos traços de personalidade maquiavélicos $(42,17 \%)$ e narcisistas (36,73\%). Esse resultado sugere que pais com maior nível de instrução podem influenciar os filhos a buscarem sucesso profissional, por meio de estratégias de estudo mais inovadoras. Já os altos traços de Psicopatia (42,85\%) foram mais evidenciados para estudantes para pais com escolaridade de ensino médio incompleto.

Os alunos que apresentaram maiores frequências para os traços mais altos de Maquiavelismo (39,08\%), Narcisismo (31,57\%) e Psicopatia $(31,21 \%)$ são oriundos de escolas de ensino médio privadas. Esse resultado permite a inferência de que a origem escolar motiva a concepção de os estudantes se sentirem mais bem preparados, confiantes e mais competitivos que aqueles oriundos de escola pública, sobretudo pelas dificuldades enfrentadas no ensino público brasileiro.

\begin{tabular}{|c|c|c|c|c|}
\hline \multirow{2}{*}{$\begin{array}{c}\text { Variável } \\
\text { Dependente }\end{array}$} & \multirow{2}{*}{ Teste } & Maquiavelismo & Narcisismo & Psicopatia \\
\hline & & Sig & Sig & Sig \\
\hline Gênero & Mann-Whiney &, $\left.000{ }^{(* *}\right)$ &, $\left.001{ }^{(* *}\right)$ &, $000\left(^{* *}\right)$ \\
\hline Faixa etária & Kruskal-Wallis & ,062 &, $\left.010{ }^{(* *}\right)$ &, $000\left(^{* *}\right)$ \\
\hline AtivRem & Mann-Whiney &, $000\left(^{* *}\right)$ & ,647 & 143 \\
\hline Renda & Mann-Whiney &, $002\left({ }^{* *}\right)$ &, $\left.000{ }^{(* *}\right)$ & ,340 \\
\hline EscPais & Kruskal-Wallis &, $000\left(^{* *}\right)$ &, $003(* *)$ &, $001(* *)$ \\
\hline EnsMed & Kruskal-Wallis &, $000\left(^{* *}\right)$ &, $033(* *)$ &, $000(* *)$ \\
\hline
\end{tabular}

Nota: AtivRem: Atividade remunerada; EnsMédio: Ensino Médio, EscPais: escolaridade dos pais; EnsMédio: Tipo de instituição em que foi cursado o ensino médio.

$(* *) p<, 05$.

Fonte: Dados da pesquisa (2017)

Esses resultados permitem a inferência de que as características demográficas e sociais dos estudantes de Ciências Contábeis acentuam ou inibem a exteriorização dos traços de personalidade do Dark Traid e, consequentemente, refletem nos comportamentos daqueles no meio acadêmico.

Isto posto, com o propósito de confirmar os resultados anteriores, aplicou-se a regressão logística, devido à natureza dicotômica da variável dependente face à variável independente métrica e às variáveis potencialmente influenciadoras. 
Tabela 12: Regressão logística: valores culturais, traços de personalidade do Dark Triade variáveis demográficas e sociais

\begin{tabular}{|c|c|c|c|c|c|}
\hline & Variável & Sinal esperado & Sinal encontrado & Coeficiente B & Coeficiente $\operatorname{Exp}(\beta)$ \\
\hline \multirow{10}{*}{ Masculinidade } & Maquiavelismo & + & + & 402 & $1,495(* * *)$ \\
\hline & Narcisismo & + & + &, 538 & $1,713(* *)$ \\
\hline & Psicopatia & + & - & ,065 & 0,937 \\
\hline & Gênero & & & & - \\
\hline & Faixa etária & & & & - \\
\hline & AtivRem & & & & - \\
\hline & Renda & & & & - \\
\hline & EscPais & & & & - \\
\hline & EnsMed & & & & Sim \\
\hline & Constante & + & - & 3,479 &, $031(* * *)$ \\
\hline \multirow{10}{*}{ Individualismo } & Maquiavelismo & + & + & 693 & $2,001(* * *)$ \\
\hline & Narcisismo & + & + & 376 & $1,4566^{(* * *)}$ \\
\hline & Psicopatia & + & - & ,035 & 966 \\
\hline & Gênero & & & & - \\
\hline & Faixa etária & & & & - \\
\hline & AtivRem & & & & Sim \\
\hline & Renda & & & & - \\
\hline & EscPais & & & & - \\
\hline & EnsMed & & & & - \\
\hline & Constante & + & - & 4,398 &, $012(* * *)$ \\
\hline \multirow{10}{*}{ Distância do poder } & Maquiavelismo & + & + & 600 & $1,823(* * *)$ \\
\hline & Narcisismo & + & + &, 338 & $1,402(* * *)$ \\
\hline & Psicopatia & + & + & ,311 & $1,365(* * *)$ \\
\hline & Gênero & & & & Sim \\
\hline & Faixa etária & & & & - \\
\hline & AtivRem & & & & - \\
\hline & Renda & & & & Sim \\
\hline & EscPais & & & & - \\
\hline & EnsMed & & & & - \\
\hline & Constante & + & - & 5,218 & $135,9199^{(* *)}$ \\
\hline
\end{tabular}

Legenda: AtivRem: Atividade remunerada; EscPais: Escolaridade dos pais; EnsMed: Tipo de instituição em que foi cursado o ensino médio.

Nota1: Masculinidade: Obs.: 1404; Sig:,000; Qui-Quadrado: 160,655: PseudoR²:, 144.

Nota 2: Individualismo: Obs.: 1404; Sig: ,000; Qui-Quadrado: 229,489; PseudoR²:,201.

Nota 3: Distância do poder: Obs.: 1404; Sig:,000; Qui-Quadrado: 301,018; PseudoR²:,257.

$\left(^{* * *}\right) p<0,01$

Fonte: Dados da pesquisa (2017)

Na Tabela 12, observa-se que as variáveis Maquiavelismo e Narcisismo são significativas e possuem sinal positivo, evidenciando que a variação positiva dessas variáveis concorre para o aumento da probabilidade de os estudantes concordarem com as atitudes masculinas, quando as demais variáveis permanecerem constantes. Resultado similar se observa para o Individualismo.

A Psicopatia, que não tinha sido preditora para as atitudes de Masculinidade e Individualismo, apresentou-se positiva e significativa, assim como o Maquiavelismo e o Narcisismo, para estimar a probabilidade de concordância dos estudantes com as atitudes de Distância do poder. As variáveis gênero e renda também se mostraram positivas para o modelo.

Sumariamente, os resultados do estudo permitem confirmar as hipóteses $\mathrm{H1}, \mathrm{H} 2, \mathrm{H} 3, \mathrm{H} 4$, conforme tabela 13. 
Table 13: Resumo dos resultados das hipóteses de pesquisa

\begin{tabular}{|l|l|}
\hline \multicolumn{1}{|c|}{ Hipóteses } & Decisão \\
\hline $\begin{array}{l}\text { H1: Existe uma correlação significativa entre os traços que compõe o Dark Triad e os valores } \\
\text { culturais de Masculinidade, Individualismo e Distância ao poder. }\end{array}$ & Rejeitar H0 \\
\hline $\begin{array}{l}\text { H2: Os estudantes de Ciências Contábeis com altos traços de personalidade que compõe o Dark } \\
\text { Triad são mais propensos a valores masculinos. }\end{array}$ & Rejeitar H0 \\
\hline $\begin{array}{l}\text { H3: Os estudantes de Ciências Contábeis com altos traços de personalidade que compõe o Dark } \\
\text { Triad são mais propensos a valores individualistas. }\end{array}$ & Rejeitar H0 \\
\hline $\begin{array}{l}\text { H4: Os estudantes de Ciências Contábeis com altos traços de personalidade que compõe o Dark } \\
\text { Triad são menos propensos à aceitação de valores culturais da Distância ao poder. }\end{array}$ & Rejeitar H0 \\
\hline
\end{tabular}

Fonte: Dados da pesquisa (2017)

Os resultados apresentados permitem traçar um perfil de personalidade e dos valores cultural, demográficos e sociais da amostra em estudo e chama a atenção para o debate profícuo sobre o assunto.

\section{CONCLUSÃO}

Os achados desse estudo chamam a atenção e corroboram a preocupação de que a personalidade influencia as atitudes dos aspirantes à profissão contábil, sobretudo porque indivíduos ricos nos traços de narcisismo, por exemplo, por necessidade de admiração pública, sentem que têm autoridade para tirar do ambiente qualquer pessoa que possa ameaçá-lo; o maquiavelista usa a estratégia para obter vantagens, independentemente de prejudicar seus parceiros; e o psicopata, de forma impulsiva, agarra o que quer sem se preocupar se vai prejudicar alguém.

O traço do Maquiavelismo se destacou, indicando maior concordância dos estudantes para as assertivas"não é prudente contar meus segredos"e "existem coisas que eu escondo de outras pessoas, porque elas não precisam saber". Os valores culturais individualistas também se sobressaíram entre os demais, sobretudo pela concordância de que "A autorrealização é base para o sucesso", "a autoestima é imprescindível para minha motivação na universidade e/ou trabalho" e"a relação de trabalho é uma transação comercial e não familiar".

Observou-se ainda que os valores culturais dos estudantes se diferenciam e se associam positivamente na presença dos três traços do Dark Triad. A manifestação excessiva de características de assertividade, foco no sucesso material, competitividade, ambição, autorrealização, autoestima, autointeresse, relação de troca vantajosa e calculista podem implicar comportamentos que comprometem a conduta do estudante em sala de aula e na vida profissional, além provocar um ambiente masculino e individualista. Por outro lado, os estudantes que demonstraram serem mais dotados dos traços não aceitaram as desigualdades sociais, dependência, subordinação e não receiam expressar desacordo de decisões de superiores. Isso implica um novo olhar dos estudantes sobre a hierarquia na família e no ambiente acadêmico e profissional, o que pode ocasionar boas posturas quando manifestadas de forma moderada.

Os achados sugerem ainda que os estudantes do sexo masculino e oriundos da escola privada apresentaram maior disposição para as características da tríade, implicando que os estudantes do sexo masculino são mais maquiavélicos, narcisistas e psicopatas. No que se refere à escolaridade dos pais, aqueles que possuem Especialização, Mestrado e Doutorado têm filhos com maior disposição para traços maquiavélicos e narcisistas, implicando que quanto maiores as titulações dos pais, maior a influencia para o uso de estratégias e ambição. E os estudantes que possuem ensino médio incompleto, têm filhos com maior disposição para traços de psicopatia.

Por fim, evidenciou-se que os três traços corroboram com a probabilidade de os alunos exteriorizarem valores culturais individualistas e masculinos. Esses achados, portanto, sinalizam aos sujeitos 
envolvidos no processo ensino-aprendizagem a percepção de que existe uma relação entre os traços de personalidade do Dark Triad e os valores culturais e permite a discussão sobre a elaboração de políticas educacionais e cursos de capacitação sobre a ética, com o objetivo de apresentar aos alunos as consequências atitudes que remetam a valores culturais individualistas e aos altos traços de personalidade do Dark Triad.

Este estudo limita-se a essas análises, sem, contudo, adentrar nos aspectos técnicos ou práticos sobre a educação contábil, embora os resultados chamem a atenção aos educadores sobre a importância e maior ênfase à IES 4 (2015) que aponta a que a educação contábil deve estar pautada em princípios éticos e atitudes que considerem independência, objetividade, integridade, sigilo, confiabilidade, compromisso e responsabilidade. Assim, sugere-se a continuidade dos estudos, especialmente para se investigar, de forma comparativa, estudantes brasileiros, com estudantes de outras nacionalidades, a fim de observar se os valores culturais e os traços de personalidade se modificam em comparação aos resultados aqui obtidos.

REFERÊNCIAS

Allport, G. W. (1937). Personality:a psychological interpretation. Oxford, England: Holt.

Allport, G. W. (1961). Pattern and growth in personality. Oxford, England: Holt.

Alves Filho, E. M. (2016). Cultura organizacional de cursos de ciências contábeis: um estudo em duas universidades públicas.(Tese de Doutorado em Controladoria e Contabilidade, Universidade de São Paulo).

Auyeung, P., \& Sands, J. (1997). Factors influencing accounting students' career choice: a cross-cultural validation study. Accounting Education, 6(1), 13-23. https://doi.org/10.1080/096392897331596

Avelino, B. C.; Lima, G. A. S. F. de. (2014). A influência do narcisismo no ambiente acadêmico: aspectos relacionados à desonestidade. Anais do Congresso USP de Controladoria e Contabilidade, São Paulo, SP, Brasil, 14.

Bailey, C. D. (2015). Psychopathy, Academic accountants' attitudes toward unethical research practices, and publication success. The Accounting Review, 90(4), 1307-1332. https://doi.org/10.2308/accr-50970

Baughman, H. M., Jonason, P. K., Lyons, M., \&Vernon, P. A. (2014). Liar liar pants on fire: Cheater strategies linked to the Dark Triad. Personality and Individual Differences, 71, 35-38. https://doi.org/10.1016/j. paid.2014.07.019

Bogdanovic, M., \& Cingula, D. (2015). Dark triad of croatian management students. Central European Business Review, 4, 30-47.

Bowditch, J. L., \& Buono, A. F. (1992). Elementos de comportamento organizacional. São Paulo: Pioneira.

Briggs, S. P., Copeland, S. \& Haynes, D. (2007). Accountants for the 21st century, where are you? A five-year study of accounting students' personality preferences. Critical Perspectives on Accounting, 18(5), 511537. https://doi.org/10.1016/j.cpa.2006.01.013

Brislin, R. W., \& Lo, K. D. (2006). Culture, personality, and people's uses of time: Key interrelationships. In J. C. Thomas, \& D. L. Segal (Ed.). Comprehensive handbook of personality and psychopathology. (vol. 1, Chap 3, pp. 44-61). New Jersey: Wiley, John Wiley \& Sons, Inc.

Brunell, A. B., Staats, S., Barden, J. \& Hupp, J. M. (2011). Narcissism and academic dishonesty: The exhibitionism dimension and the lack of guilt. Personality and Individual Differences, 50, 323-328. https:// doi.org/10.1016/j.paid.2010.10.006 
Casagrande, R. M. (2009). Dimensões da cultura organizacional no modelo de Hofstede: estudo em uma empresa brasileira internacionalizada. Dissertação de mestrado Universidade Regional de Blumenau, Blumenau, SC, Brasil.

Christie, R., \& Geis, F. L. (1970). Studies in machiavellianism. New York: Academic Press. Academic Press. D'Souza, M. F. (2016). Manobras financeiras e o Dark Triad: o despertar do lado sombrio na gestão. Tese de doutorado, Universidade de São Paulo, São Paulo, SP, Brasil.

D'Souza, M. F., Lima, G. A. S. F. de, Jones, D. N. \& Carre, J. R. (2019). Eu ganho, a empresa ganha ou ganhamos juntos ?: traços moderados do dark triad e a maximização de lucros. Revista de Contabilidade \& Finanças, 30(jan/abr.2019), pp. 123-138. http://www.scielo.br/scielo.php?script=sci_arttext\&pi$\mathrm{d}=$ S1519-70772019000100123\&lng=en\&tIng=en

D'Souza, M. F. \& Lima, G. A. S. F. de. (2018). Escolha de carreira: o Dark Triad revela interesses de estudantes de Contabilidade. Revista De Contabilidade E Organizações, 12, e151837. https://doi.org/10.11606/ issn.1982-6486.rco.2018.151837

D'Souza, M. F. \& Lima, G.A.S.F. (2015). The dark side of power: the dark triad in opportunistic decision-making. Journal Advances in Scientific and Applied Accounting, 8(2), pp. 135-156. https://doi: 10.14392/ asaa.2015080201.

Freud, S. (1914). Introdução ao narcisismo. In S. Freud. Obras completas. Tradução Paulo César de Souza. São Paulo: Companhia das Letras (v. 12, 2010).

Garcia D., Adrianson L, Archer T, Rosenberg, P. (2015). The Dark Side of the Affective Profiles. SAGE Open 5, 1-14. https://doi.org/10.1177/2158244015615167

Gray, S. J. (1988). Towards a theory of cultural influence on the development of accounting systems internationally. Abacus, 24(1), 1-15. https://doi.org/10.1111/j.1467-6281.1988.tb00200.x

Hamann, E. V. (2011). Influência cultural sobre os estilos de aprendizagem dos estudantes de Ciências Contábeis do Distrito Federal: um estudo empírico sobre as abordagens de Hofstede e Kolb. Dissertação de mestrado, Universidade de Brasília, Brasília, DF, Brasil.

Hambrick, D. C. (2007). Upper echelons theory: an update. Academy of Management Review, 32(2), 334-343. https://doi.org/10.5465/amr.2007.24345254.

Harrison, G. L., \& McKinnon, J. L. (1999). Cross-cultural research in management control systems design: a review of the current state. Accounting, Organizations and Society, 24(5), 483-506. https://doi.org/10.1016/ S0361-3682(97)00048-2

Hofstede, G. (1984). Culture's consequences international differences in work-related values. Beverly Hills, CA: Sage.

Hofstede, G. (2001). Culture's consequences: comparing values, behaviors, institutions and organizations across nations. 2a ed. Thousand Oaks CA: Sage Publications.

Hofstede, G. (2003). Cultura e organizações: compreender a nossa programação mental. Trad. Antônio Fidalgo. Lisboa: Edições Sílabo.

Hofstede, G., \& Mccrae, R. R. (2004). Personality and culture revisited: linking traits and dimensions of culture. Cross-cultural Research, 38(1), 52-88. https://doi.org/10.1177/1069397103259443

Hofstede, G., Hilal, A. V. G. de Malvezzi, S., Tanure, B., \& Vinken, H. (2010). Comparing regional cultures within a country: lessons from Brazil. Journal of Cross-Cultural Psychology, 41(3), 336-352. https://doi. org/10.1177/0022022109359696 
International Education Standart (IES, 2, 3 e 4). (2015). In: Handbook of International Education Pronouncements Edition. New York, 2015. Disponível em: <http://www.ifac.org.>

Jakobwitz, S., \& Egan, V. (2006). The dark triad and normal personality traits. Personality and Individual differences, 40(2), 331-339. doi:10.1016/j.paid.2005.07.006

Johnson, E. N., Kuhn, J. R., Jr., Apostolou, B., \& Hassell, J. M. (2012). Auditor perceptions of client narcissism as a fraud attitude risk factor. Auditing: A Journal of Theory \& Practice, 32(1), 203-219. https://doi. org/10.2308/ajpt-50329

Jonason, P. K., Foster, J., Oshio, A., Sitnikova, M., Birkas, B., \& Gouveia, V. (2017). Self-construals and the Dark Triad traits in six countries. Personality and Individual Differences, 113, 120-124. https://doi.org/10.1016/j. paid.2017.02.053

Jonason, P. K., Webster, G. D., Schmitt, D. P., Li, N. P., \& Crysel, L. (2012). The antihero in popular culture: Life history theory and the dark triad personality traits. Review of General Psychology, 16(2), 192. https:// doi.org/10.1037/a0027914

Jones, D. N. \& Paulhus D. L. (2009). Machiavellianism. In M. R., Leary, \& R. H., Hoyle. (Ed.). Individual differences in social behavior. (Chap. 7, pp. 93-108). New York: Guilford.

Jones, D. N., \& Paulhus, D. L. (2014). Introducing the short Dark Triad (SD3): a brief measure of dark personality traits. Assessment, 21(1), 28-41. https://doi.org/10.1177/1073191113514105

Judge, T. A., Piccolo, R. F., \& Kosalka, T. (2009). The bright and dark side of leader traits: a review and theoretical extension of the leader trait paradigm. The Leadership Quarterly, 20(6), 855-875. https://doi. org/10.1016/j.leaqua.2009.09.004

Kovar, S. E.; Ott, R. L.; Fisher, D. G. (2003). Personality preferences of accounting students: a longitudinal case study. Journal of Accounting Education, 21(2), 75-94. https://doi.org/10.1016/S0748-5751(03)00008-3

Kroeber, A. L.; Kluckhohn, C. (1952). Culture: a critical review of concepts and definitions. Papers. Peabody Museum of Archaeology \& Ethnology, Harvard University.

Lima, R. N., Souza, A. Filho, \& D'Souza, M. F. (2016). Narcissistic personality traits in the context of accounting education: an application of the item response theory. Anais do Encontro da Associação Nacional de Pós-graduação e Pesquisa em Administração, Salvador, BA, Brasil, 40.

Lin, Z. J., Xiong, X., \& Liu, M. (2005). Knowledge base and skill development in accounting education: Evidence from China. Journal of Accounting Education, 23(3), 149-169. https://doi.org/10.1016/j.jaccedu.2005.06.003

Majors, T. M. (2015). The Interaction of Communicating Measurement Uncertainty and the Dark Triad on Managers' Reporting Decisions. The Accounting Review, 91(3), 973-992. https://doi.org/10.2308/ accr-51276

Mohamed, E. K., \& Lashine, S. H. (2003). Accounting knowledge and skills and the challenges of a global business environment. Managerial Finance, 29(7), 3-16. https://doi.org/10.1108/03074350310768319

Nair, P., \& Kamalanabhan, T. J. (2010). The impact of cynicism on ethical intentions of Indian managers: the moderating role of seniority. Journal of International Business Ethics, 3(1), 14.

O’Boyle, E. H., Jr., Forsyth, D. R., Banks, G. C., \& McDaniel, M. A. (2012). A meta-analysis of the Dark Triad and work behavior: a social exchange perspective. Journal of Applied Psychology, 97(3), 557-579. http:// dx.doi.org/10.1037/a0025679 
Ott, E., Cunha, J.V. A. da, Cornacchione., E. B. Jr., \& De Luca, M. M. M. (2011). Relevância dos conhecimentos, habilidades e métodos instrucionais na perspectiva de estudantes e profissionais da área contábil: estudo comparativo internacional. Revista Contabilidade \& Finanças, 22(57), 338-356. https://doi.org/10.1590/ S1519-70772011000300007

Paulhus, D. L., \&Williams, K. (2002). The DarkTriad of personality: narcissism, machiavellianism, and psychopathy. Journal of Research in Personality, 36(6), 556-563. https://doi.org/10.1016/S0092-6566(02)00505-6 Peter, J., \& Olson, J. (2009). Comportamento do consumidor e estratégia de marketing. 8a. ed. São Paulo: McGraw-Hill.

Raskin, R., \& Terry, H. (1988). A principal-components analysis of the narcissistic personality inventory and further evidence of its construct validity. Journal of Personality and Social Psychology, 54(5), 890-902. doi:10.1037/0022-3514.54.5.890

Rauthmann, J. F., \& Will, T. (2011). Proposing a multidimensional Machiavellianism conceptualization. Social Behavior and Personality: an international journal, 39(3), 391-403. https://doi.org/10.2224/ sbp.2011.39.3.391

Robertson, S. A., Datu, J. A. D., Brawley, A. M., Pury, C. L., \& Mateo, N. J. (2016). The Dark Triad and social behavior:The influence of self-construal and power distance. Personality and Individual Differences, 98, 69-74. https://doi.org/10.1016/j.paid.2016.03.090

Shome, A., \& Rao, V. H. (2009, Outubro). Machiavellianism in public accountants: some additional Canadian evidence. Business Ethics: A European Review, 18(4), 364-371. https://doi.org/10.1111/j. 1467-8608.2009.01569.x

Sugahara, S., \& Boland, G. (2010). The role of cultural factors in the learning style preferences of accounting students: a comparative study between Japan and Australia. Accounting Education: An International Journal, 19(3), 235-255. https://doi.org/10.1080/09639280903208518

Teoh, H. Y., Serang, D. P., \& Lim, C. C. (1999). Individualism-collectivism cultural differences affecting perceptions of unethical practices: some evidence from Australian and Indonesian accounting students. Teaching Business Ethics, 3(2), 137-153. https://doi.org/10.1023/A:1009832018849

Vandenbos, G. R. (Org.). (2010). Dicionário de Psicologia da American Psychological Association (D. Bueno et al., Trad.) Porto Alegre: Artmed.

Weffort, E. F. J. (2005). O Brasil e a harmonização contábil internacional: influências dos sistemas jurídico e educacional, da cultura e do mercado. Editora Atlas SA.

Wheeler, P. (2001). The Myers-Briggs Type Indicator and applications to accounting education and research. Issues in Accounting Education, 16(1), 125-150. https://doi.org/10.2308/iace.2001.16.1.125

Yetiser, B. (2014). Do all roads lead to Rome? The moderating role of culture and age in predicting construal level on machiavellianism. Journal of Yaşar University, 9(36), 6261- 6380. 